\title{
Diplomasi Politik Indonesia Terhadap Kemerdekaan Palestina
}

\author{
Muh. Novan Prasetya, Aulia Srifauzi \\ Program Studi Hubungan Internasional \\ Universitas Potensi Utama \\ Email: muhnovanprasetya@gmail.com
}

\begin{abstract}
Abstrak
Berjuang untuk kemerdekaan Palestina adalah sebuah janji Indonesia saat menggelar Konferensi Asia Afrika (KAA) pertama di Bandung tahun 1955. 29 Negara peserta yang hadir pada saat itu, hanya Palestina yang belum meraih kemerdekaan. Maka dari itu, Indonesia sangat gencar menyuarakan kepentingan tentang kemerdekaan Palestina dari dulu hingga masa kini. Untuk Indonesia, Palestina bukan hanya persoalan agama begitu juga dukungan Indonesia terhadap perjuangan kemerdekaan Palestina bukan hanya tentang kepentingan Indonesia. Maka karena itu, seluruh upaya dalam mendukung Palestina untuk memperjuangkan hak dan kemerdekaannya bukan hanya merupakan kepentingan Indonesia tapi seluruh pemangku kepentingan di dunia internasional. Dengan mendukung perjuangan kemerdekaan Palestina menunjukkan pentingnya keadilan untuk kemanusiaan di dunia ini. Terkait dukungan tersebut, Indonesia sendiri telah melakukan beragam upaya diplomasi untuk menggalang kekuatan internasional dalam membela serta memperjuangkan hak Palestina untuk merdeka. Saat Konferensi Luar Biasa OKI di Istanbul, Presiden Joko Widodo menyampaikan 6 poin usulan sikap seluruh negara anggota OKI terhadap Amerika Serikat yang mendeklarasikan Jerusalem sebagai ibu kota Israel. Dalam tulisan ini penulis berusaha menyampaikan bahwa luka palestina ada duka dunia.
\end{abstract}

Kata Kunci: Kemerdekaan Palestina, Diplomasi Indonesia, OKI.

\begin{abstract}
Fighting for Palestinian independence is the promise of Indonesia since holding the Asia Africa Conference (KAA) in Bandung in 1955. Of the 29 countries present, only Palestine has not been independent. Therefore, Indonesia incentive to voice the interests of Palestine from the past until today. For Indonesia, Palestine is not a matter of religion and Indonesia's support for the struggle for Palestinian independence is not just the interests of Indonesia. Therefore, efforts to support the Palestinians in their fight for rights and freedoms are in the interest of Indonesia and all stakeholders in the international arena. This shows the importance of justice and humanity in the world. Related to the support, Indonesia has made various diplomatic efforts to raise international powers in defending and fighting for the rights of the Palestinian people. At the OIC Conference in Istanbul, Turkey, President Joko Widodo conveyed 6 recommendations of OIC member states stance on US steps that recognize Jerusalem as the capital of Israel. In this paper the author tries to convey that the wounds of the Palestinians are the sorrows of the world.
\end{abstract}

Key Word: Palestinian Independence, Indonesia Diplomasi, OIC. 


\section{PENDAHULUAN}

\section{a. Latar Belakang}

Indonesia dalam melakukan politik luar negeri dan diplomasi ditujukan untuk memastikan terjaminnya kepentingan nasional Indonesia, tujuan pembangunan nasional, pertumbuhan ekonomi, kesejahteraan rakyat, konsolidasi demokrasi dan pencapaian keadilan sosial (Buku Diplomasi, 2014). Sejalan dengan dinamika hubungan Internasional pada level kawasan maupun global, kebijakan politik luar negeri dan diplomasi Indonesia tetap mengacu pada pelaksanaan politik bebas aktif. Politik bebas dan aktif yaitu politik luar negeri yang dianut Indonesia dengan tidak bergabung atau terpengaruh dengan alasan politik dan mengecam, akan tetapi aktif mewujudkan perdamaian dunia, sesuai dengan Undang-Undang Dasar 1945, berdasarkan kemerdekaan, perdamaian abadi, dan keadilan sosial. Dalam prakteknya, Indonesia melaksanakan hubungan kerjasama bilateral, kerja sama kawasan, dan kerja sama multilateral (Buku Diplomasi, 2014). Hal tersebut adalah upaya diplomasi Indonesia dalam mewujudkan kepentingan nasionalnya berdasarkan politik luar negeri bebas aktif. Seperti penjelasan di atas selain untuk mewujudkan kepentingan nasionalnya Indonesia juga berusaha mewujudkan terciptanya perdamaian dunia, salah satunya adalah perjuangan diplomasi politik Indonesia untuk Palestina yang akan dibahas melalui tulisan ini.

Palestina adalah Negara di kawasan timur tengah yang hingga kini berusaha mendapatkan kedaulatannya sendiri dan diakui oleh dunia Internasional. Konflik berbau politik yang mendera menjadikan Palestina hingga kini belum bisa mewujudkan mimpinya untuk menjadi negara merdeka dan berdaulat. Diperparah dengan terjadinya konflik internal antara dua organisasi kuat yaitu Hamas dan Fatah yang akhirnya menyebabkan terpecahnya Palestina menjadi dua wilayah kekuasaan, wilayah Tepi Barat (West Bank) dikuasa oleh partai Fatah dan partai Hamas menguasai wilayah Jalur Gaza (Gaza Strip) (Carter, 2010).

Konflik antara Palestina dan Israel yang terbaru adalah ketika Amerika sebagai pendukung utama Israel secara kontroversial mengakui Yerusalem sebagai ibukota Israel yang dimana sejatinya Yerusalem adalah bagian dari Palestina. Pengumuman yang disampaikan Donald Trump pada 6 Desember 2017 tersebut memicu kemarahan dan demonstrasi besarbesaran umat Muslim di seluruh dunia. Dalam demonstrasi menuntut keadilan pasca 
pengakuan sepihak Israel tentang Yerusalem, dari pertama kali diadakannya demonstrasi hingga mei 2018 lebih dari 13.000 warga Palestina menjadi korban cedera dan 114 meninggal oleh serangan militer Israel (merdeka, 2017).

Indonesia yang mempunyai prinsip bahwa segala bentuk penjajahan tidak sejalan dengan perikemanusiaan dan perikeadilan menentang segala bentuk penjajahan yang ada di muka bumi, salah satunya yang di lakukan negara Israel terhadap Palestina. Dan juga, Indonesia sebagai negara dunia ketiga yang berpenduduk mayoritas muslim mempunyai kesamaan pandangan tehadap agama dengan Palestina yaitu islam, yang juga dimana mempunyai kesamaan presepsi untuk menjaga tempat yang dianggap suci dan penuh sejarah yaitu Masjidil Aqsa di Jerussalem. Hubungan antar negara yang baik antara Indonesia dan Palestina mendorong Pemerintah Indonesia melakukan berbagai langkah inisiatif untuk berperan serta dalam membantu penanganan korban agresi Israel dan perjuangan kemerdekaan negara Palestina.

Menurut sejarah, hubungan bilateral yang terjalin antar Indonesia dan Palestina sudah sangat lama, sejak masa peralihan menuju kemerdekaan hingga pengakuan kemerdekaan Negara Indonesia. Palestina sendiri merupakan bangsa yang pertama di kawasan TimurTengah yang menyebarluaskan kemerdekaan Indonesia pada Radio Internasional melalui Mufti Palestina yang bernama Amin Al-Husaini. Berkat jasa inilah, kemerdekaan Indonesia mendapatkan gema kemerdekaanya pada masyarakat Internasional dunia.

Tulisan ini berupaya untuk menganalisis berbagai upaya yang dilakukan oleh Negara Indonesia untuk membantu kemerdekaan Palestina. Tulisan ini mencoba mengidentifkasi bahwa Negara Indonesia merupakan negara yang mendukung kemerdekaan negara lain dengan penghapusan penjajahan di atas dunia. Tulisan ini berusaha menjelaskan argumen yang mendukung berbagai pernyataan diatas. Tulisan ini dibagi menjadi empat bagian pembahasan, yaitu penguraian mengenai perjuangan Palestina, uraian mengenai bantuan Indonesia kepada palestina, serta menjabarkan upaya-upaya yang telah dilakukan Pemerintahan Indonesia dilihat dari segi politik dan keterlibatan masyarakat Indonesia dalam menyuarakan kemerdekaan Palestina. 


\section{b. Landasan Teori}

\section{Teori Politik Luar Negeri}

Landasan politik luar negeri Indonesia adalah pancasila sebagai pedoman bagi kehidupan berbangsa dan bernegara yang ideal mencakup seluruh aspek kehidupan manusia. Landasan konstitusional politik luar negeri Indonesia adalah UUD 1945 alinea pertama dan alinea keempat, alinea pertama berbunyi :

"Bahwa sesungguhnya kemerdekaan itu ialah hak segala bangsa dan oleh sebab itu maka penjajahan di atas dunia harus dihapuskan karena tidak sesuai dengan perikemanusiaan dan perikeadilan" (Redaksi Sumber Media, 2013).

Alenia keempat pembukaan UUD 1945 berbunyi :

"...ikut melaksanakan ketertiban dunia yang berdasarkan kemerdekaan, perdamaian abadi, dan keadilan social”. (Redaksi Sumber Media, 2013).

Untuk merealisasikan hal tersebut Indonesia menganut sistem politik bebas aktif. Menurut Hatta, politik "Bebas" adalah Indonesia tidak memilih antara kedua blok dan lebih memutuskan jalannya sendiri untuk mengatasi masalah internasional. Makna “Aktif” adalah upaya agar berusaha lebih giat demi menjaga perdamaian dan meredakan ketegangan antara kedua blok. (Hatta, 1976).

Dalam pelaksanaa politik luar negeri dan hubungan luar negeri, Indonesia terikat oleh ketentuan hukum dan kebiasaan internasional yang merupakan dasar bagi pergaulan dan hubungan antar Negara. Oleh karena itu Undang-undang tentang Hubungan Luar Negeri sangat penting artinya, mengingat Indonesia telah meratifikasi Konversi Wina 1961 tentang Hubungan Diplomatik, Konvensi Wina 1963 tentang Hubungan Konsuler, dan Konvensi tentang Misi Khusus, New York 1969. Undang-Undang Nomor 37 Tahun 1999 tentang Hubungan Luar Negeri merupakan pelaksanaan dari ketentuan dasar yang tercantum di dalam Pembukaan dan Batang Tubuh Undang-Undang Dasar 1945 dan Ketetapan-ketetapan Majelis Permusyawaratan Rakyat yang berkenaan dengan hubungan luar negeri. Undang-undang ini mengatur segala aspek penyelenggaraan hubungan luar negeri dan pelaksanaan politik luar negeri, termasuk sarana dan mekanisme pelaksanaannya, perlindungan kepada warga negara Indonesia di luar negeri dan aparatur hubungan luar negeri. 
Menurut Ganewati Wuryandari (2008), mengutip dari Chirs Brown di buku karangannya Understanding International Relations memberi gambaran secara lugas tentang seluruh kebijakan politik luar negeri dipahami sebagai metode untuk menggambarkan perjuangan kepentingan nasional sebuah negara terhadap dunia internasional. Pernyataan tersebut dapat diartikan bahwa setiap politik luar negeri dan kepentingan nasional sebuah negara tak terpisah antara satu dan lainnya. Selanjutnya, wuryandari turut memberi penjelasan perbedaan antara dua pandangan juga berkaitan dengan kepentingan nasional sebuah negara itu. Yang pertama adalah pendekatan objektif, yang memberi penilaian bila setiap kepentingan nasional negara yaitu hal yang dapat diartikan dengan jelas menggunakan sesuatu yang objektif hingga peraturan nasional sebuah negara akan tetap setiap saat. Hingga pada sisi lain, pandangan kedua lebih bersifat subjektif yang menilai kepentingan nasional yaitu hal yang akan berubah tergantung pandangan subjektif setiap pembuat kebijakan, Paham ini menghasilkan tanggapan setiap kepentingan negara dan setiap sisi-sisi yang ditampakkan dan kebijakan yang menjadi hasil dapat bergantung paham, preferensi serta sikap pembuat kebijakan (Wuryndari, 2008:15).

Dari setiap penguraian sebelumnya kita dapat menarik kesimpulan bahwa setiap kebijakan yang diambil Pemerintah RI untuk penyelesaian konflik di Timur Tengah terkhusus Palestina. Dalam konteks perjuangan kemerdekaan Palestina, Indonesia dengan teguh ikut berperan dalam perjuangan negara Palestina sejalan Konstitusi Republik Indonesia bahwa menantang setiap hal berbentuk di muka bumi. Cita-cita dari Indonesia yang bertujuan agar dunia yang damai dapat terwujud dan seluruh hal berbentuk penjajahan didunia mesti dilenyapkan adalah kebijakan negara Indonesia yang senantiasa dipegang teguh sejak dulu hingga kapanpun. Kemudian ada apa penyelesaian dengan konflik Israel dan Palestina menjadi tujuan utama Indonesia? Ini berdasar pendapat Indonesia konflik antara Palestina dan Israel adalah sumber setiap permasalahan di Timur Tengah, serta proses damai yang terus tertunda dan berlarut semakin membuat buruk keadaan diwilayah Timur Tengah hingga kedamian akan semakin sulit tercapai.

Landasan hukum yang dipakai oleh Indonesia demi membantu perjuangan kemerdekaan Palestina adalah Resolusi DK 242 (1967) dan 338 (1973) berisi agar seluruh wilayah Palestina harus dikembalikan tidak bersyarat yang dijajah oleh Israel serta seluruh hak sah bangsa Palestina untuk dapat menentukan kemerdekaannya, menegakkan bangsa di tanah 
airnya dan al-Quds al-Syarif di Jerussalem Timur adalah ibu kota serta berpedoman Tanah yang penuh kedamaian (Dirjen Multilateral Deplu RI, 2008:11).

\section{PEMBAHASAN}

\section{a. Dinamika Perjuangan Palestina}

Perjuangan Palestina untuk meraih kemerekaan telah dimulai pada tahun 48, sesaat sesudah pihak Israel dengan sendiri mendeklarasikan negara Israel di tanah Palestina. Bersama dukungan dari seluruh negara Timur Tengah, Upaya pengusiran di lakukan oleh Palestina tapi kegagalan diperoleh yang berakhir kekuasaan Israel ditanah Palestina semakin bertambah. Ditahun 64 didirikanlah Palestine Liberation Organization (PLO) (Gerner,2006). PLO sendiri adalah inti dari setiap organisasi resmi untuk membebaskan Palestina pada masa itu serta menolak dengan lugas pengakuan atas negara Yahudi di muka bumi ini. Hanya PLO satusatunya yang diakui sebagai organisasi yang mewakili Palestina di dunia Internasional. Di tahun 1969, Organisasi Kerjasama Islam (OKI) memberi Pengakuan resmi terhadapa PLO sebagai perwakilan resmi bangsa Palestina di kancah internasional. Yang akhirnya saat 22-1174 The United Nation General Assembly akhirnya mengakui keberadaan PLO sebagai organisasi resmi bangsa Palestina.

PLO mendeklarasikan bahwa negara Palestina telah berdiri di Aljiria, ibukota dari Aljazair pada Pada 15 November 1988. Tak lama dari itu, Israel dengan berbagai negara besar yang memberi dukungan seperti Amerika (US) enggan memberi pengakuan terhadap deklarasi merdeka yang dilakukan oleh Palestina. Serta dilain sisi, Israel masih urung menghentikan penjajahannya pada tanah Palestina. Lain hal pada Persatuan Bangsa-Bangsa, walau PLO telah diakui dan telah resmi menjadi anggota peninjau sebagai perwakilan Palestina pada tahun 74 , Kemerdekaan yang di gaungkan oleh Palestina tak kunjung merubah nasibnya sedikitpun. Palestina mulai mengganti upaya perjuangannya untuk meraih kemerdekaan yaitu mencoba jalur diplomasi. Palestina mengakui keberadaan israel secara tidak langsung pada tahun 1993 saat menerima hasil perancangan jalan keluar "dua negara" dari solusi yang diberikan oleh Persatuan Bangsa-Bangsa No: 181 di tahun 47, berisi tanah Palestina terbagi jadi dua negara teruntuk Israel dan Palestina sesuai setiap batas wilayah yang telah tercantum dalam solusi 
tersebut. kemudian Israel sendiri mengaku terhadap kelegalan dari organisasi PLO serta terbuka terhadap usaha untuk membahas langkah damai dari dua pihak, dua negara tersebut mulai mengakui keberadaan masing-masingnya yang akhirnya membuahkan hasil perjanjian yang disebut Kesepakatan di Oslo pada September 93.

Upaya diplomasi untuk mencapai kedamaian antara Palestina dan Israel terus dilakukan dengan bantuan dari pihak lain diantaranya Amerika (US). Dari usaha ini dihasilkan beragam kesepakatan, yaitu:

1. Kesepakatan di Oslo II tahun 95.

2. Way River tahun 98 dan Camp David II tahun 2000,

3. Arab Initiative Peace and Road Map.

Sayangya dari berbagai upaya tersebut Amerika Serikat cenderung memihak pada Israel dalam penyelesaian konflik Palestina antar Israel ini (Gerner,2006).

Telah banyak perundingan dan kesepakatan yang telah dilakukan namun tidak ada kesepakatan yang benar-benar berujung kedaulatan penuh untuk Palestina. Bahkan fakta yang terdapat Israel masih tetap punya kuasa untuk mengontrol di wilayah Palestina, seperti terbangunnya pemukiman Yahudi yang tidak resmi di wilayah Palestina dan penyerangan militer di tanah Palestina yang beralasan membasmi terorisme tapi faktanya yang menjadi korban adalah warga sipil. Dari berbagai kekejian yang dilakukan Israel, Palestina mulai melakukan upaya agar kedaulatannya diakui oleh dunia internasional, agar menguatkan posisinya dalam hal menawar pengakuan de jure untuk Palestina adalah sebuah negara yang berdaulat sesuai perbatasan territorial wilayah pada tahun 67 yang telah disepakati (Kusumaningrum, 2011). Pada tahun 2011, Palestina yang dikomandoi oleh Mahmoud Abbas berupaya mengajukan proposal agar ditetapkan menjadi anggota penuh di Persatuan BangsaBangsa. Namun Palestina gagal mendapat rekomendasi dari Dewan Keamanan PBB pada 11 november 2011. Palestina tidak menyerah dan di tahun selanjutnya, Palestina meneruskan usahanya dengan pengajuan resolusi untuk membuat Palestina menjadi negara peninjau pada Persatuan Bangsa-Bangsa lewat Majelis Umum PBB (UNISPAL, 2012). 
Indonesia adalah sebuah negara dari berbagai negara yang sangat optimis untuk membantu Palestina dalam meriah kemerdekaan dan kedaulatannya. Hal yang menjadi pondasi dari prinsip Indonesia tercantum dalam Konstitusi Negara, yang menegaskan bahwa Indonesia menentang segala bentuk penjajahan yang ada, dan tentunya Faktor Agama adalah faktor penguat lainnya atas sikap Indonesia. Indonesia mempunyai masyarakat muslim terbesar di dunia yang tentunya menjadi landasan dari simpati terhadap perjuangan Palestina meraih kemerdekaan. Menurut M. Muttaqien (Muttaqien, 2013) pertentangan antara Arab dan Israel adalah isu yang sangat penting untuk politik luar negeri Indonesia itu sendiri, oleh karena itu tanggapan masyarakat yang berterkaitan isu dari konflik ini mesti jadi pembahasan penting bagi pengambil kebijakan untuk mengambil sikap terhadap kepentingan internasonal Indonesia. Selain komitmen Indonesia untuk mewujudkan penghapusan segala bentuk penjajahan dimuka bumi, Indonesia juga adalah anggota aktif dari berbagai organisasi internasiona, seperti Gerakan Non Blok dan Organisasi Kerjasama Islam yang mempunyai perhatian khusus terhadap konflik Palestina dan Israel ini. Sehingga merupakan hal yang sangat penting bagi Indonesia dalam menunjukkan komitmennya untuk mendukung dan memperjuangkan Palestina untuk meriah kemerdekaannya. Sebagai contoh upayanya yaitu dengan merangkul berbagai dukungan dari negara-negara lain untuk peningkatan status anggota Palestina di Persatuan Bangsa-Bangsa.

\section{b. Peran OKI dan PBB dalam upaya perdamaian Palestina}

Konflik Palestina dan israel merupakan salah satu tujuan didirikannya Organisasi Konfrensi Islam atau OKI. Setelah dibentuknya OKI sebagai wadah bagi kekuatan islam, tidaklah sedikit peran yang telah dilakukan OKI dalam mengupayakan perdamaian dan kemerdekaan bagi Palestina dari tangan rezim Israel. OKI turut memainkan peran yang berarti bagi perdamaian Palestina, selain itu perjuangan OKI adalah upayanya untuk meraih dukungan dari berbagai pihak didunia internasional atas pengakuan kemerdekaan Palestina sebagai sebuah negara berdaulat. Berbagai upaya dilakukan OKI dalam mengambil sikap pada setiap ketimpangan yang dilakukan Israel. Maka itu, OKI sadar tidak punya cara lain agar mencapai perdamaian di Palestina, selain menjadi Negara yang merdeka seutuhnya (Buku Diplomasi, 2014). 
Menurut Ihsanoglu sebagai sekertaris jendral OKI menyatakan bahwa ada 3 pasal kesepakatan jadi penegasan terhadap posisi OKI untuk memberi dukungan kepada kemerdekaan palestina. Ini juga termasuk mengkecam Israel yang tak berhenti menjajah tanah dan wilayah Palestina. Solusi lain yang direncanakan yaitu menyelenggarakan Sidang Umum Persatuan Bangsa-Bangsa berjudul "United For Peace" serta menjalankan berbagai langkah untuk dapat memberi hukuman kepada Israel.

Tujuan dari Organisasi Konfrensi Islam (OKI) sendiri merupakan organisasi yang dibentuk sebagai reaksi dari peristiwa pembakaran masjid Al-aqsa yang terletak di kota Al-quds atau yerusalem pada tanggal 21 Agustus 1961. Lalu kejadian tersebut menimbulkan reaksi keras dari kalangan umat islam. Akibat kejadian tersebut, muncul aksi dikalangan Negara-negara islam untuk menggalang kekuatan umat islam dalam rangka pembebasan yerusalem sebagai tempat suci ketiga umat islam. Kesadaran umat islam pun semakin bangkit dengan mengadakan Konferensi Tingkat Tinggi (KTT) pertama di Rabat, Maroko Pada bulan September 1969.

Dalam berbagai KTT yang dilaksanakan OKI memang tidak lepas dari permasalahan timur tengah, seolah-olah OKI hanya dibentuk untuk Timur tengah. Kesan tersebut tidak dapat dipungkiri sepenuhnya, karena salah satu persoalan dan kemelut dunia yang menjadi perhatian masyarakat internasional terjadi dikawasan arab dan timur tengah. Sedangkan dalam OKI sendiri persoalan timur tengah dan palestina terlihat lebih menonjol karena terkait didalamnya pembicaraan dan desakan yang bernafaskan kepentingan agama dan umat islam seluruh dunia. Dan pada dasarnya OKI itu bertujuan untuk menciptakan perdamaian dan keamanan dunia muslim secara garis besar dan memperkokoh solidaritas islam antar Negara dan anggotanya apalagi lebih untuk bisa membela Negara palestina dari Israel.

Lalu pada bulan juli 2011, Organisasi Konferensi Islam (OKI) mendesak perserikatan bangsa-bangsa (PBB) agar mengakui status kedaulatan palestina. Namun pihak antara Palestina dan Israel bersikukuh bahwa punya hak atas tanah Palestina. Kedua pihak berseteru tentang merekalah bangsa yang sangat berhak atas tanah Palestina. Sikap PBB untuk menangani permasalahan ini harus netral dan tidak boleh berat sebelah. Namun kenyataan yang terjadi bahwa PBB seolah lebih berpihak pada Israel ketimbang membela kepentingan 
palestina. Dalam perkara ini tentunya anggota dewan keamanan PBB sangat punya peran besar dalam menanggulangi krisis dipalestina. Namun Amerika Serikat sebagai polisi dunia seolah bungkam dan tidak mau tahu atas apa yang terjadi dipalestina. Yang menjadi ironis yaitu Amerika Serikat sebagai Negara penyumbang dana terbesar Israel. PBB seolah tidak berani untuk ikut campur terhadap krisis yang terjadi disana. Padahal PBB punya tugas menjaga perdamaian dan ketertiban dunia. Dan seharusnya PBB punya sikap yang tegas terhadap Israel.

PBB juga seolah terdokrin oleh amerika serikat untuk tidak melakukan intervensi berlebihan terhadap konflik tersebut. Berbagai skema perundingan yang ditawarkan pihak PBB terhadap Israel dan palestina mulai dari perjanjian Camp David sampai perjanjian Oslo tidak secara serta merta mampu meredam konflik antara kedua Negara tersebut. Sejauh apapun upaya PBB dalam konflik ini akan sangat tidak berarti tanpa ada dukungan dari Negara adidaya seperti Amerika Serikat. Selain peran PBB dan Amerika Serikat, Israel dan palestina sendiri pun juga harus bisa menjajaki hubungan baik antar kedua Negara. Walaupun kita tahu bahwa palestina sudah sangat Underestimate terhadap Israel dengan track record yang pernah terjadi.(Academia,2016)

\section{c. Hubungan Bilateral Palestina-Indonesia}

Indonesia sendiri adalah negara yang berpegang teguh pada prinsip sistem politik luar negeri yang bebas dan aktif, arti dari sistem politik yang di pegang oleh Indonesia yaitu politik negara yang mengandung kemerdekaan dan kedaulatan Negara serta berdasarkan pada kepentingan rakyat dan bertujuan untuk perdamaian di dunia. Dalam prakteknya sendiri, salah satu bentuk hubungan Indonesia dengan negara lain adalah hubungan bilateral Indonesia dengan negara-negara di kawasan Timur Tengah, seperti hubungan bilateral Indonesia dengan Palestina.

Hubungan antara Palestina dan Indonesia sendiri telah terjalin sejak awal kemerdekaan Indonesia. Palestina dan Mesir menjadi negara pertama yang memberi pengakuan terhadap deklarasi merdeka Indonesia. Indonesia mengirim tim delegasinya ke negara-negara timur tengah dan disambut dengan ramah serta mendapat dukungan oleh Syaikh Muhammad Amin 
Al-Husaini yang dimana adalah mufti dari Palestina yang akhirnya turut berperan dalam perundingan Indonesia keberbagai negara Timur Tengah untuk pengakuan terhadap kedaulatan negara Indonesia. Sehingga kemudian Mesir turut mengakui kedaulatan negara Indonesia untuk pertama kalinya di 22 Maret 96 yang negara Timur Tengah lain mengikutinya.

Indonesia adalah negara berdaulat yang aktif menentang penjajahan Israel atas Palestina sejak kemerdekaannya, Meski dalam hal ini telah mengakui kemerdekaan Indonesia di tahun 1950 tapi hingga kini Indonesia masih tidak memberi pengakuan terhadap Israel. Pada tahun 74 Indonesia memberi pengakuan terhadap Palestine Liberation Organization (PLO) yang dipimpin oleh YasserArafat sebagai perwakilan rakyat Palestina diranah dunia. Pada tahun 88, akhirnya Palestina memberi deklarasi terhadap kemerdekaannya sendiri pada 15 November di Aljazair. Dihari berikutnya 16 November, Indonesia pun memberi pengakuan kemerdekaan negara Palestina serta mulai menjalin hubungan diplomatiknya. Indonesia sendiri enggan mempunyai hubungan diplomatiknya dengan Israel bila mereka tetap melakukan penjajahan. Pada tahun 91, kantor Kedutaan Besar Palestina akhirnya resmi berada di ibu kota Indonesia. Pada tahun 1993 Yasser Arafat sebagai Presiden palestina, mengunjungi Indonesia yang bertujuan menemui presiden Soeharto.

Setelah kemenangan partai Hamas di tahun 2006 pada pemilhan umum, Indonesia memberi selamat dan memberi penghormatan kepada rakyat Palestina telah menyelenggarakan pemilhan umum dengan cara demokratis, Indonesia juga mengajak negaranegara barat yang tidak mengakui hasil pemilhan umum yang dimenangkan oleh Hamas untuk tidak berperasangka buruk (Muttaqien,2015). Pada tahun 2007 kemudian tahun 2010, presiden Mahmoud Abbas melakukan kunjungan kerja ke Indonesia untuk memperat kerjasama dibidang ekonomi dan pendidikan, dan dalam kunjungan tersebut Palestina juga meminta bantuan Indonesia untuk menghidupkan kembali proses perdamaian dan rekonsiliasi internal Palestina, terkhusus antar partai Hamas dan Fatah (Diplomasi, 2014). 


\section{d. Peran Indonesia Dalam Perjuangan Kemerdekaan Palestina}

Kemerdekaan Palestina bukanlah pilihan politik luar negeri Indonesia. Namun hal ini sudah merupakan keharusan karena adanya amanah konstitusi. Ada sisi lain, di mana konflik Israel-Palestina juga tidak begitu kunjung selesai, tercatat pada kurun 2007-2008 dan pada tahun bulan juni 2018 lalu Indonesia terpilih lagi untuk keempat kalinya sebagai anggota tidak tetap Dewan Keamanan (DK) PBB. Hal ini memberikan keuntungan Indonesia dalam konteks sebagai wadah untuk mengekspresikan politik luar negeri dan diplomasinya terutama untuk Palestina.

Keanggotaan Indonesia di DK PBB diwarnai dengan aktifnya diplomasi Indonesia dalam usaha-usaha penyelesaian masalah konflik Palestina-Israel. Indonesia memandang konflik Israel-Palestina dengan perhatian tersendiri. Sebagai negara dengan populasi muslim terbesar di dunia, 206.635.753 orang (87\% total penduduk) dan pernah mengalami jajahan, Indonesia memiliki rasa perhatian yang tinggi untuk membantu Palestina yang juga mayoritas muslim. Indonesia konsisten mendukung kemerdekaan bangsa Palestina ditinjau dari masa pemerintahan Presiden Joko widodo. Hal ini tersebut dibuktikan pada saat Konferensi Tingkat Tinggi Luar Biasa OKI di Istanbul Turki, presiden jokowi mengatakan,

"Dalam setiap helaan nafas diplomasi Indonesia, di situ terdapat keberpihakan terhadap palestina" (Biro Pers, 2017).

Dari pernyataan di atas, dapat dilihat bahwa Indonesia sebagai bangsa yang tegas dalam mendukung kemerdekaan palestina, selain dukungan politik Indonesia juga turut memberikan dukungan moril pada negara Palestina. Ketegasan Indonesia dalam mendukung kemerdekaan Palestina dibuktikan dengan tidak membuka hubungan resmi baik dagang ataupun diplomatik dengan negara Israel. Hal ini secara tidak langsung menunjukan bahwa Indonesia tidak mengakui adanya Israel sebagai sebuah negara dengan tidak melakukan hubungan bilateral dengan negara tersebut.

Konsistensi dukungan Indonesia terhadap Palestina juga terlihat dari respon Indonesia terhadap kebijakan Presiden Amerika Serikat yaitu Trump yang memberikan pengakuan terhadap Yerusalem sebagai ibu kota Israel (Geotimes, 2017), Indonesia melalui presiden Joko 
widodo mengeluarkan 6 usulan tegas dalam merespon hal tersebut, ke-enam usulan tersebut antara lain pertama, OKI harus secara tegas menolak pengakuan bilateral dari Amerika Serikat terkait Yerusalem tersebut. Yerusalem Timur adalah Ibu Kota Palestina. Kedua, Semua negara yang memiliki keduataan di Tel Aviv tidak mengikuti keputusan AS. Ketiga, negara anggota OKI diminta untuk menjadi motor penggerak dukungan negara-negara lain yang belum mengakui untuk dapat mengakui Palestina, Keempat, negara anggota OKI yang memiliki hubungan diplomatik dengan Israel sebaiknya segera mengambil langkah diplomatik sesuai dengan resolusi OKI. Kelima, negara-negara OKI diminta untuk mengambil langkah bersama meningkatkan bantuan kemanusiaan, peningkatan kapasitas dan kerjasama ekonomi dengan Palestina. Keenam, OKI harus mampu menjadi motor pergerakan di berbagai forum internasional atau multilateral untuk membantu Palestina.

Pernyataan tersebut menunjukan bahwa Presiden Jokowi mengecam tindakan yang dilakukan oleh Amerika Serikat dengan mengajak negara anggota yang tergabung kedalam OKI dalam mengaplikasikan ke-enam usulan tersebut. Pemerintah Indonesia mendorong agar segera mengadakan sidang khusus untuk menangani masalah ini. Selain dukungan pemerintah peran masyarakat Indonesia sendiri merupakan hal yang sangat besar bagi terjalinnya hubungan yang erat antara Indonesia dan Palestina, hal tersebut tidak terlepas dari cerminan bangsa Indonesia sebagai bangsa yang menghormati kebebasan kemerdekaan bangsa dan manusia seperti pada sila ke 2 pancasila yaitu Kemanusiaan yang adil dan beradab.

Komitmen yang dijalankan pemerintah dan rakyat Indonesia dalam memperjuangkan kemerdekaan palestina merupakan tanggung jawab bagi dunia Internasional. Indonesia melalui presiden Joko widodo menunjukan bahwa politik luar negeri Indonesia bebas aktif berjalan melalui realisasi diplomasi politik kemerdekan Palestina. Hal tersebut menunjukan Indonesia sebagai negara yang mengekang keras penjajahan dan ketidak adilan. Indonesia akan terus mengupayakan kemerdekaan Palestina agar terwujud karena setiap helaan nafas diplomasi Indonesia terdapat keberpihakan kepada Palestina. 


\section{KESIMPULAN}

Pemerintah Indonesia berharap penyelenggaraan KTT luar biasa OKI akan menghasilkan Deklarasi Jakarta yang berisi kesepakatan bersama Negara-negara OKI dalam penyelesaian konkret permasalahan palestina. Indonesia juga berharap agar masalah palestina bisa kembali kedalam radar perhatian internasional melalui KTT yang mengambil tema "United for a just solution". Untuk bisa menjadi mediator dan mewujudkan perdamaian didunia dengan menuntaskan konflik Israel dan palestina, Indonesia tidak bisa sendirian. Perlu pendekatan yang intensif dengan Negara-negara lain, termasuk dengan Israel, untuk bisa mendamaikan Israel dan palestina, karena pemerintah Indonesia juga akan menemui kesulitan jika menyelesaikan konflik itu hanya melalui OKI, dan walaupun Indonesia tidak memiliki wewenang yang sama besarnya dengan amerika dalam PBB, Indonesia konsisten menyuarakan hak-hak rakyat palestina, dan membantu dalam mempromosikan agar palestina mendapatkan Negara yang merdeka.

Indonesia bersama dengan negara anggota OKI terus gencar menyuarakan kemerdekaan untuk negara Palestina. Hal tersebut merupakan bentuk dari komitmen negara Indonesia dalam memperjuangkan kemerdekaan Palestina. memperjuangkan kemerdekaan Palestina bukanlah hal yang mudah, berbagai kepentingan mulai dari politik dan agama turut mewarnai hal ini. Indonesia tidak gentar melawan negara adidaya yang memiliki kepentingan besar dalam masalah ini yaitu Amerika Serikat. Indonesia terus melakukan upayanya untuk mendorong terwujudnya kemerdekaan Palestina. Indonesia tidak tinggal diam dengan selalu memberikan dukungan kemanusian ataupun politik, masyarakat Indonesia juga berperan besar dalam memberikan bantuan ataupun dukungan terhadap Palestina.

Tulisan ini melihat kerja keras Indonesia dalam memperjuangkan kemerdekaan Palestina sangatlah besar, terlepas dari skema hutang budi perjuangan kemerdekaaan Palestina adalah tanggung jawab bagi seluruh dunia. Indonesia akan terus melakukan diplomasi tersebut untuk memperjuangkan hak dari setiap negara yaitu sebuah kemerdekaan yang hakiki. 


\section{DAFTAR PUSTAKA}

\section{Buku:}

1. Kementrian Luar Negeri Republik Indonesia, 2015, Diplomasi Indonesia 2014, Direktorat Informasi dan Media.

2. Hatta, Mohammad, 1976. Mendayung antara dua karang, Jakarta, Bulan Bintang,

3. Yunita Norma, 2014, Edisi terbaru dan terlengkap UUD 1945 dan Amandemen, Kunci Aksara.

4. Jimmy Carter. 2010. Palestine Peace Not Apartheid (Palestina Perdamaian Bukan Perpecahan). Jakarta : PT. Dian Rakyat.

5. Deborah J. Gerner, Kilas Balik Sejarah Palestina-Israel dalam Khalifah Magazine No. 11/Tahun I, Agustus 2006.

\section{Internet:}

Diakses pada 10 September 2018 dengan link :

http://m.tribunnews.com/nasional/2017/12/12presiden-jokowi-hadiri-ktt-luar-biasa$\underline{\text { oki-di-turki }}$ 